\title{
Changing how data are collected can change what we learn from discipline-based educational research
}

\author{
George M. Bodner \\ Department of Chemistry, Purdue University, West Lafayette, IN 47907, USA*
}

\begin{abstract}
More than 25 years ago, Boyer [1] called for an expanded definition of the term scholarship to "... break out of the tired old teaching versus research debate and define, in more creative ways, what it means to be a scholar." It is tempting to reread Scholarship Reconsidered: Priorities of the Professorate within the context of the growth in recent years of what has become known as discipline-based educational research (DBER). For the sake of argument, we will define DBER in terms of three critical elements: (1) a well-articulated set of guiding research questions, (2) an explicit choice of theoretical framework on which the study can be based, and (3) a choice of methodology that is appropriate for probing these research questions. This paper will discuss these three elements of a good educational research study, look at several theoretical frameworks we have used for our chemical education research, examine a model of five domains of project evaluation, and provide an introduction to Action Research as a framework upon which to build a tightly coupled implementation and evaluation design for curriculum reform projects.
\end{abstract}

\section{INTRODUCTION TO THE CHEMICAL EDUCATION RESEARCH PROGRAM AT PURDUE}

The CER program at Purdue can be traced back to April, 1981, when Dudley Herron and I received permission to create a program that would lead to M.S. and/or Ph.D. degrees in chemical education. Three years later, we published a paper in which we outlined our goals for the program [2]. We noted that our colleagues "... showed a certain amount of faith that chemical education is an area of scholarship worthy of the status afforded established branches of chemistry." Twentyfive years later, we published a paper in the same journal that summarized what we had accomplished [3]. As of the date this is being written, we have graduated $96 \mathrm{Ph} . \mathrm{D}$.'s.

\section{METAPHOR ON WHICH THE TITLE OF THE PAPER IS BASED}

Twenty years ago, I noticed an article on the front page of US Today that reported the results of a study by Bailar and Gornik [4] of the success, or lack thereof, of the "War on Cancer" that was declared by President Nixon in 1971. The authors of the study chose to measure progress against cancer using mortality rates from 1950 to 1994 because this was "the most basic measure of progress against cancer" and "the outcome that is most reliably reported." They concluded that "... 35 years of intense effort focused largely on improving treatment must be judged a qualified failure." I will assert, however, that fundamentally different conclusions would have been reached if they had examined other forms of progress, such as changes in the length of survival or changes in the

\footnotetext{
* George M. Bodner, Arthur E. Kelly Distinguished Professor of Chemistry, Education and Engineering at Purdue University, West Lafayette, IN and Head of the Division of Chemical Education at Purdue. Contact information: gmbodner@purdue.edu, (765) 494-5313.
}

quality of life after cancer is diagnosed. In other words, this study provides a concrete example of what I believe is a basic characteristic of study design: The choice of methodology can have an enormous effect on the conclusions reached.

\section{THREE ELEMENTS OF GOOD EDUCATIONAL RESEARCH DESIGN}

In a paper based on my ACS Pimentel Award address [5], I argued that there are three elements of good educational research design: (1) A set of guiding research questions the study will try to answer, (2) a theoretical framework consistent with the research questions upon which the study will be built, and (3) a methodology that is appropriate for probing these research questions.

\section{A. Assertions about guiding research questions}

Let's look at two examples of guiding research questions we have used.

- What are engineering students' perceptions and experiences of computational simulations as learning tools? [6]

- How does the acculturation of graduate students into the community of practice of organic chemists affect their approaches to solving organic synthesis problems? [7]

The first study differentiated between "computer simulations" that are written for use by students and "computational simulations" written for use by practicing scientists or engineers that are then incorporated into an undergraduate course. The second looked at what can be done to facilitate the process of "acculturation" whereby students pick up the skills and values that enable them to be a member of the community of practice in their field. 
I have argued that guiding research questions not only can, but should evolve in the course of a study [5]. Consider, for example, a study of students enrolled in a course on quantum mechanics [8]. The original research question proposed by the graduate student doing this study was: How do students learn quantum mechanics? Several weeks into the data collection he concluded the answer was: Not very well. The revised questions became: (1) What are the experiences of students learning quantum mechanics?, (2) What conceptual difficulties do students have with quantum mechanics?, and (3) How do students approach learning quantum mechanics?

\section{B. Assertions about methodology}

I first started doing research in 1965. I soon learned that I might be many things, but I am not a synthetic chemist. So I became a spectroscopist in the early days of Fourier Transform NMR [9]. For roughly 30 years, I have been involved in doing discipline-based educational research (DBER). My conclusion from more than 50 years of doing research in chemistry and then educational research is simple: The quality of the insight obtained is proportional to the difficulty of doing an experiment or study. As you might therefore expect, I am not "fond" of research based on Likert scales and am committed to the use of qualitative interview techniques.

\section{Assertions about quantitative research}

Let me begin by noting that there is nothing inherently wrong with quantitative research. As can be seen in a review of the evolution of our work on problem solving in chemistry, we started this work using traditional statistical techniques [10]. But let me also assert there is nothing inherently right about quantitative research, either. My group soon learned that studies based on statistical techniques were not going to help us understand what we were interested, i.e., the difference between successful problem solvers and those who are not successful. It is therefore roughly 30 years since we used quantitative research methods.

Patton [11] has noted: "Quantitative methods are succinct, parsimonious, and easily aggregated for analysis; quantitative data are systematic, standardized, and easily presented in a short space." I agree with every aspect of this quote.

There is an old joke, however, about a drunk searching for a lost set of keys by a lamppost; not because that is where it was dropped, but because that is where the light is. This can be traced back to A. E. Housman, a noted British poet and classicist, who noted: “... he uses statistics like a drunk uses lampposts, more for support than illumination."

People who teach educational research methods courses often claim that quantitative research is "generalizable." I disagree; it is no more generalizable than other research methods because there are invariably differences between the institution where a particular statistical study is done and your classroom in terms of the nature of the student population, the textbook used, the way the course was taught, the exams used to assess student understanding, and a host of other factors.

\section{ASSERTIONS ABOUT QUALITATIVE RESEARCH}

There is general agreement that qualitative research sacrifices the objectivity that results from rigid statistical research designs for a combination of flexibility, depth, and detail. (Three characteristics of research results that I value.) As someone who teaches a course on the philosophy of science for senior-level science majors, I understand the call for "objectivity" in research. But I am also quite aware of the validity of the following: "Objectivity is the myth that you can make an observation in the absence of an observer" [12].

It has been suggested that qualitative research is done by individuals with a preference for hypothesis-generating research, rather than hypothesis-testing research. (A fundamental characteristic of most of the research we have done in the last 30 years.)

As qualitative researchers often note: "Qualitative data describe. . . . They capture and communicate someone else's experience of the world in his or her own words. Qualitative data tell a story" [13]. Qualitative research provides information about questions that revolve around better-better decisions about how to study quantum mechanics, for example, or a better understanding of the "curved arrow" formalism used by organic chemists to visualize the mechanism of a reaction.

Although I know that this is going to get me into trouble with so many of my colleagues who teach educational research methods course, I am going to argue that the results of qualitative research are "transferrable," if not fully generalizable.

As evidence for this, I would like to cite a study that followed a student given the pseudonym "Parker" through the first semester of an organic chemistry course taken by chemistry majors [14]. "Parker" had done very well in the general chemistry course for majors the previous year. He was a "good" student, who came to class, read the textbook, did homework problems, studied for exams, and so on. He was particularly good at remembering concepts he had learned in general chemistry. By the end of the first semester of the organic course, however, he switched to political science.

Once the course got past the first few chapters of the textbook, "Parker" became lost. The details of what happened and why this happened is not likely to be important for readers of this paper. What is important is my argument that if I've got a "Parker" in my class, anyone else teaching organic chemistry is likely to have a "Parker" in theirs. Furthermore, I am going to argue that there are a limited number of different kinds of students going through a given course. If we learn to understand a handful of exemplars we can improve instruction for many, if not most, of the students enrolled in the course in a given semester. 


\section{THEORETICAL FRAMEWORKS FOR QUALITATIVE RESEARCH}

For many years, I asked my colleagues who taught educational research methods courses if they could recommend a text that I could use with my graduate students to help them decide which theoretical framework was most appropriate for a given study. They would laugh and note that such a book did not exist. So we decided to write one [15]. The author of each chapter was asked to describe where a particular theoretical framework came from, list studies from DBER that used this framework, and then describe what happened when they used this framework for their own research. Because it is no longer being sold by the publisher, I have obtained the copyright for this book back from the publisher and will soon post it on my website [16]. For now, let's look at a few theoretical frameworks we have found useful.

\section{A. Constructivism/social constructivism}

Thirty years ago, I published a paper in which I tried to express in language chemists would understand a model of the relationship between teaching and learning known as the constructivist theory of knowledge [17]. In the first paragraph of this paper I noted that those of us who teach for a living have abundant evidence for the following hypothesis: "Teaching and learning are not synonymous; we can teach, and teach well, without having the students learn." I then went on to describe the constructivist theory of knowledge in nine words: "Knowledge is constructed in the minds of the learner."

The version of the constructivist theory I tried to describe can be labeled "personal constructivism." Another version is known as "social constructivism." I hope you will accept my argument that you don't have to choose between these models if you are willing to accept the idea that process by which knowledge is constructed in the mind of the individual is obviously influenced by others involved in the social environment in which learning takes place.

Constructivism/social constructivism can be a useful theoretical perspective — or "lens"-for studies of "meaning making" [18]. Consider the studies we have undertaken of the process by which both undergraduates [19] and graduate students [20] construct meaning of the "curved arrow" formalism organic chemists use to describe the process by which electrons are thought to flow as bonds are made/broken during the course of a chemical reaction, as shown in Fig. 1.

\section{B. Hermeneutics}

During the presentation upon which this paper is based, I asked people to raise their hands if they have ever included students in the process by which the textbook is chosen for use next year. A rough estimate would suggest that perhaps as many as $3 \%$ (but no more than this) had ever done this.

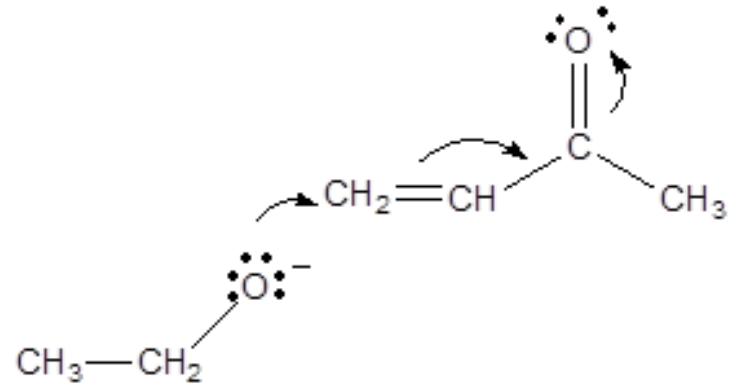

FIG. 1. The "curved arrow" formalism is used in this example to indicate how a pair of nonbonding electrons on the oxygen atom of one molecule are used to form a $\mathrm{C}-\mathrm{O}$ bond between the two molecules undergoing reaction. This displaces a pair of electrons in a $\mathrm{C}=\mathrm{C}$ double bond between the so-called $\mathrm{C}_{3}$ and $\mathrm{C}_{4}$ atoms to form a double bond between the $\mathrm{C}_{3}$ and $\mathrm{C}_{2}$ atoms. This, in turn, displaces a pair of electrons in the $\mathrm{C}=\mathrm{O}$ double bond that become a pair of nonbonding electrons on the oxygen.

That's an interesting result. Although I would not expect anyone to let students select the textbook without input from the instructor, I can advocate that at least a few students from this year's class should be involved in the discussion of the book that will eventually be selected. If or when this is done, the instructor would be incorporating a hermeneutic framework into the process of choosing a textbook by "giving a voice" to a group who are typically ignored.

There are two different situations in which a hermeneutic framework is typically used. The most common use of this theoretical perspective would be consistent with the work that Shane [21] did when he studied high school science teachers' beliefs about the intended and actual impacts of standardsbased reforms. This was a group that could vocalize their beliefs, but were never allowed to "give voice" to their opinions to the group that makes decisions that have such a high impact on their lives.

Another approach based on a hermeneutic perspective involves quite literally giving a group a voice because the participants have not, yet, reached a stage in their lives when they can verbalize what is going through their minds. As an example, consider the work of Volkmann and Anderson [22] in which the "...teaching journal of a first-year chemistry teacher was examined to address the question: What is the nature of creating a professional identity of science teacher?" In this case, the researchers who were themselves experienced teachers, helped to "give voice" to the experiences of a firstyear teacher who might not have been able to fully vocalize what they experienced.

\section{Phenomenology vs. phenomenography}

Phenomenology and phenomenography are theoretical frameworks that are easily confused. Both of them deal with the way people experience a particular phenomenon, such as 
a particular chemistry or physics course.

Phenomenology tries to reduce the experiences people have of a particular phenomenon to a single common meaning, the "essence of the experience" that is shared by all [23, 24]. This essence has been described as "the very nature of the phenomenon. . . that which makes a 'something' what it is" [24]. Consider the experience of being a father (or mother). Phenomenology asks: What is the essence of this experience shared by all; e.g., being a father (or mother)? Or, what is the shared experience of everyone who takes the sophomorelevel organic chemistry course for majors?

Some readers might share my skepticism about the idea that one can distill what happens when all of the people who experience a phenomenon-even one as basic as the idea of being a father (or mother) - into a single, common "essence." They might therefore prefer the theoretical framework known as phenomenography, which tries to understand differences in the way people experience a shared phenomenon [25-27]. Phenomenography assumes there are differences in the way individuals experience a given phenomenon, such as taking an introductory physics course. But it also assumes that there is not an endless number of different ways. Thus, it might be possible to reduce the number of different ways down to a relatively small number.

As an example of the use of phenomenography as a theoretical framework let's consider the first step that might be taken toward creating a workshop to help students learn how to study chemistry. It is easy to defend what we did [28]; we started by asking: How do students approach the task of studying for an exam now?

Another example was based on my experience when I was first given an appointment in the School of Engineering Education at Purdue. My colleagues in engineering claimed that what they did differed from science because: "Engineers do design." I vehemently disagreed. One of the examples I cited was synthetic organic chemistry, which is intrinsically an exercise in design. I then invoked the Large Hadron Collider at CERN as an example of the critical role that design plays in the practice of "doing physics." We therefore got interested in the ways experts in a wide variety of fields experience design using the perspective of phenomenography [29].

\section{Critical Theory}

The primary goal of Critical Theory is to achieve social justice by overcoming situations in which there is an uneven balance of power. Within the context of the teaching/learning of topics such as chemistry or physics, Critical Theory invokes the concept of "emancipatory knowledge." When I invoke this concept in conversations with other chemists, I ask them to think about learning how to ride a bicycle or drive a car. Everyone seems to agree that this is a form of "knowledge." But it is also emancipatory because, as I joke, the response to the question: "Where are you going?" becomes: "Out." In different ways and to a significantly different degree, both of these forms of knowledge fulfill the definition of emancipation in the form of liberating someone from restraint. If there is any doubt about the legitimacy of these skills as emancipatory knowledge, note that the legal definition of emancipatory is "to release (a child) from the control of parents or a guardian."

As an example of the use of Critical Theory as a theoretical framework, let me cite work we have done with students who are blind in which we asked them to draw illustrations of some of the common shapes (or geometries) encountered in simple compounds such as $\mathrm{CH}_{4}, \mathrm{PF}_{5}, \mathrm{SF}_{6}$, and so on. Consider the drawing shown in Fig. 2. Most people assume this is a tetrahedron. But they're wrong; it is a drawing of a structure known as a trigonal bipyramid. Without exception every sighted person I have known has drawn the trigonal bipyramid as shown in Fig. 3, i.e., from a horizontal perspective. The drawing in Fig. 2, however, is from a vertical perspective. It clearly shows the atom at the top of the bipyramid and the three atoms in what is known to chemists as the equatorial plane. There is a small bump that represents the atom at the center of this structure, and, then, of course, the atom at the bottom of the bipyramid is obstructed by the atom in the center.

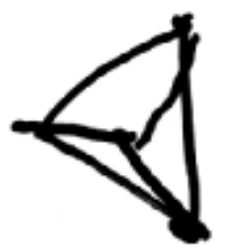

FIG. 2. What is the shape (or geometry) for which the following diagram was drawn by a student who was blind?

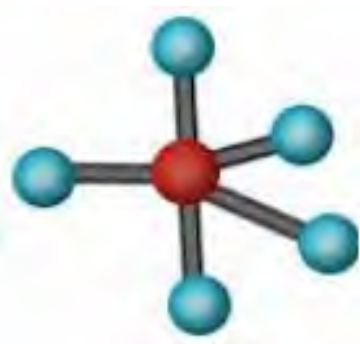

FIG. 3. The drawing in the previous figure is not a tetrahedron; it is a trigonal bipyramid drawn from a vertical perspective. This is a shape that is always represented by sighted individuals from the horizontal perspective, shown here.

Our long-term goal is to provide ways for students to successfully complete the high-school chemistry course [30], the introductory college-level chemistry course [31], and then the sophomore-level organic chemistry course. Our goal is not necessarily to increase the number of blind chemists, although that number is increasing. It is to provide students with blindness with the emancipatory knowledge that will 
enable them to pursue a variety of STEM careers because they are no longer locked out of general chemistry or organic chemistry.

\section{THEORETICAL FRAMEWORKS FOR ASSESSMENT/EVALUATION}

The theoretical frameworks for discipline-based educational research are useful tools for assessment/evaluation studies. Let me start this section by noting that most chemists I know use these terms more or less interchangeably, as if they were synonyms. They are not. One can assess students as part of the evaluation of a program [32].

The traditional approach to evaluation assumes the change being made is either "good" or "bad." Usually however, the effect is bipolar; some students benefit from the change, others do not. The traditional approach fails to ask the important question: cui bono?-who benefits from the change that was made in either what was taught or how it was taught.

\section{THE DIFFERENT DOMAINS OF ASSESSMENT/EVALUATION}

\section{A. Conventional domain}

Billy Crystal tells a story about coming home one day and noting that his grandfather was watching a basketball game, so he asked: "What's the score?," only to be told "88-86." So he asked, "Who's winning?", only to be told: "88."

If you asked your colleagues: "What is an appropriate way to evaluate the success of a change in either what is taught or how it is taught?" they are likely to recommend a comparison of the performance of an experimental versus control group of students. While there is nothing inherently wrong about this approach, there is nothing inherently right, either. What conclusion can be made if you get " 88 " vs " 86 "? How big does the difference have to be to validate this approach? What do you conclude if there is no difference? In essence, we are trying to find an alternative to what we have called the "sports mentality approach" to assessment/evaluation [33].

It is easy to understand why so many people would start with conventional wisdom and compare students in experimental and control groups. But let's recognize that there are too many variables that have an effect on student performance to base evaluation of a program solely on the basis of assessment of their performance.

\section{B. The affective domain}

Perhaps the students don't do much better, but, hopefully, they don't seem to be doing much worse on exams. So let's recognize that sometimes our goal is to improve students' attitude toward the course; in other words the improvement might only be found in the affective domain. Anyone who has witnessed what happens when a change in the way a course is delivered leads to a significant improvement in student attitude toward the course might be tempted to place a value on this effect that is at least as important as an improvement in students' performance on exams.

\section{The retention domain}

How about improvements in the domain of retention of knowledge/understanding? Sometimes we should make changes in our course because they improve students' retention of information from one class to another, and nothing else. You might still have to revisit ideas from the previous course when they come up in your course, but wouldn't you place a high value on improved retention of information/understanding as students go through your program?

\section{The domain of transfer}

I have been teaching chemistry for 45 years and have had more than 50,000 students enroll in my courses. The vast majority of these students were required to take the course. If they same can be said about your courses, any evaluation of our courses would not be complete without an examination of the domain known as transfer [34]. Perhaps one of the aspects of our course we should make a priority is meeting the goal of the departments we serve by improving the way we prepare students to apply what they have learned to later courses in other fields.

\section{E. The domain of acculturation}

Acculturation is a voluntary process whereby an individual adopts or adapts to a different culture. In the context of developing a model for program evaluation, we can think about it as the process by which an individual learns how to become a member of what is known as a "community of practice;" a group of people who share a profession and learn how to do it better by interacting regularly [35]. If your experience has been anything like mine, you might understand why I have put such a strong emphasis on making changes in my courses with only one goal in mind-helping students "think more like a chemist." In other words, facilitating the process of acculturation that transforms "students" into "practicing chemists" by changing the way they approach problems, such as the design of a synthesis of a complex organic compound [20]. 


\section{F. The five domains of program evaluation}

For at least 50 years, there has been a common feature of curriculum development/reform projects: Far, far more effort (and money) is devoted to the aspects of development/reform than to either dissemination of the results of the project or to evaluate the effect of making the recommended changes. Furthermore, when program evaluation has been done, people have historically focused on the simplest task: Looking at the effect of the change or changes on student performance. Perhaps we need to convince ourselves, and then our colleagues, of the importance of bringing a far broader perspective to the design of evaluation by recognizing the role that probing the affective, retention, transfer, and acculturation domains can play in making the best decisions about what aspects of changes in our courses should be valued. Each of these additional domains of program evaluation is more difficult than the traditional approach, but the added effort is worthwhile; it provides a richer, more detailed picture of the effect on students of the changes we have made.

\section{ACTION RESEARCH}

Let's now look at a framework for designing a richer, more complete approach to program evaluation known as "Action Research" $[33,36]$. Action Research differs from most approaches to curriculum development/reform in many ways.

- It targets a particular group of students, rather than assuming that the change being made will help all students. E.g., the goal, this time, might be to reduce the number of "C"'s in the course.

- It doesn't create experimental/control groups in the hope that evidence for an innovation's efficacy will arise during the course of the study. It assumes that any change will have an effect; if you can't find the effect you've just done a poor job of designing the evaluation.
- It assumes that some students will benefit from an innovation, while others will not.

- It tries to maximize the benefits of the innovation and minimize its disadvantages.

- It is done with the instructor and students, not on the instructor and students.

- It has been described as an informal, qualitative, formative, subjective, interpretive, reflective, and experiential model of inquiry in which all individuals involved in the study are knowing and contributing participants $[37,38]$.

- It tightly couples the design of a curriculum development/reform project to the evaluation of this project.

- All participants in the project-students, teachers, and researchers-contribute to the selection of intervention strategies.

Figure 4 captures the cyclic nature of Action Research. The process starts with an idea or plan to solve a problem with the course. The plan is implemented, monitored and evaluated. The results of this cycle are used to revise the plan, which is then acted on, monitored, evaluated to refine the plan.

The Action Research framework was used in a study of an analytical chemistry course for non-majors in my department [39]. Year after year, this was the most hated course in the department, which is quite an achievement considering that we have full-semester courses devoted to thermodynamics and quantum mechanics. We put a graduate student in the course who attended the lectures, was available during the four-hour laboratory, met with the instructor, and so on. When she asked for volunteers from among the students to discuss ways of improving the course, virtually every one of the students volunteered. The details of the changes that were made in the next cycles would only be of interest to someone who taught analytical chemistry. The take-home message from this study is simple: Over the course of three years we were able to make changes that had a significantly positive effect on student attitude to the course.

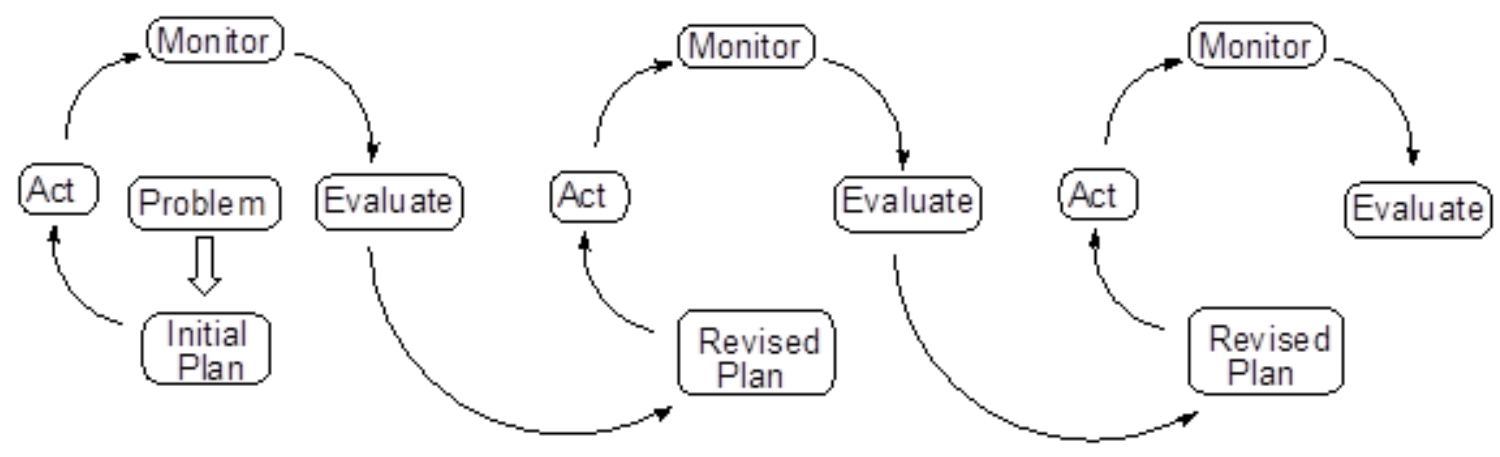

FIG. 4. The Action Research spiral [used with permission from Bodner, G. M.; Orgill, M. (Eds.) (2007). Theoretical frameworks for research in chemistry/science education, Prentice-Hall: Upper Saddle River, NJ.] 
[1] Ernest L. Boyer, Scholarship Reconsidered: Priorities of the Professoriate (Princeton University Press, Lawrenceville, NJ, 1990).

[2] George M. Bodner and J. Dudley Herron, "Completing the program with a division of chemical education," Journal of College Science Teaching 14, 179-80 (1985).

[3] George M. Bodner and Marcy H. Towns, "The Division of Chemical Education revisited, 25 years later," Journal of College Science Teaching 39, 38-43 (2010).

[4] John C. Bailar and Heather L. Gornik, "Cancer undefeated," New England Journal of Medicine 336, 1569-1574 (1997).

[5] George Bodner, "Twenty years of learning: How to do research in chemical education," Journal of Chemical Education 81, 618-628 (2004).

[6] Alejandra J. Magana, Sean P. Brophy, and George M. Bodner, "Instructors' intended learning outcomes for using computational simulations as learning tools," Journal of Engineering Education 101, 220-243 (2012).

[7] Gautam Bhattacharyya and George M. Bodner, "Culturing reality: How organic chemistry graduate students develop into practitioners," Journal of Research in Science Teaching 51, 694-713 (2014).

[8] David E. Gardner and George M. Bodner, "The existence of a problem-solving mindset among students taking quantum mechanics and its implications," in Advances in Teaching Physical Chemistry, ACS Symposium Series, Vol. 973, edited by Mark D. Ellison and Tracy A. Schoolcraft (Washington, DC: American Chemical Society, 2007) Chap. 9, pp. 155-173.

[9] George M. Bodner and Lee J. Todd, "Fourier-transform carbon-13 nuclear magnetic resonance study of (arene) tricarbonylchromium complexes," Inorganic Chemistry 13, 360-363 (1974).

[10] George M. Bodner, "Research on problem solving in chemistry," in Chemistry Education: Best Practices, Opportunities and Trends, edited by Peter W. Atkins, Javier Garcia-Martinez, and Elena Serrano-Torregrosa (John Wiley \& Sons, 2015) pp. 181-202.

[11] Michael Quinn Patton, Qualitative Research \& Evaluation Methods, 3rd ed. (SAGE Publications, Thousand Oaks, CA, 2005).

[12] E. Von Glasersfeld, Personal communication.

[13] Michael Quinn Patton, Qualitative Research \& Evaluation Methods, 4th ed. (SAGE Publications, Thousand Oaks, CA, 2014).

[14] Trisha L. Anderson and George M. Bodner, "What can we do about 'Parker'? a case study of a good student who didn't 'get' organic chemistry," Chemistry Education Research and Practice 9, 93-101 (2008).

[15] George M. Bodner and MaryKay Orgill, eds., Theoretical Frameworks for Research in Chemistry/Science Education (Prentice-Hall, Upper Saddle River, NJ, 2007).

[16] To be posted at http://chemed.chem.purdue.edu, or contact the author atgmbodner@purdue.edu.

[17] George M. Bodner, "Constructivism: A theory of knowledge," Journal of Chemical Education 63, 873-878 (1986).

[18] Robert L. Ferguson, "Constructivism and social constructivism," in Theoretical Frameworks for Research in Chemistry/Science Education, edited by George M. Bodner and MaryKay Orgill (Prentice-Hall, Upper Saddle River, NJ,
2007).

[19] Robert Ferguson and George M. Bodner, "Making sense of the arrow-pushing formalism among chemistry majors enrolled in organic chemistry," Chemistry Education Research and Practice 9, 102-113 (2008).

[20] Gautam Bhattacharyya and George M. Bodner, “"'It gets me to the product": How students propose organic mechanisms," Journal of Chemical Education 82, 1402-1407 (2005).

[21] Joseph W. Shane, "Hermeneutics and the meaning of understanding," in Theoretical Frameworks for Research in Chemistry/Science Education, edited by George M. Bodner and MaryKay Orgill (Prentice-Hall, Upper Saddle River, NJ, 2007) Chap. 6.

[22] Mark J. Volkmann and Maria A. Anderson, "Creating professional identity: Dilemmas and metaphors of a first-year chemistry teacher," Science Education 82, 293-310 (1998).

[23] Donald Polkinghorne, Methodology for the Human Sciences: Systems of Inquiry (SUNY Press, Albany, NY, 1983).

[24] Max Van Manen, Researching Lived Experience: Human Science for an Action Sensitive Pedagogy (SUNY Press, Albany, NY, 1990).

[25] Ference Marton, "Phenomenography—describing conceptions of the world around us," Instructional Science 10, 177-200 (1981).

[26] Ference Marton, "Phenomenography—a research approach to investigating different understandings of reality," Journal of Thought 21, 28-49 (1986).

[27] Ference Marton, "Phenomenography," in The International Encyclopedia of Education, Vol. 8, edited by Torsten Husén and T. Neville Postlethwaite (Pergamon, Oxford, U.K., 1994) 2nd ed., pp. 4424-4429.

[28] Kirsten Casey, "Phenomenology," in Theoretical Frameworks for Research in Chemistry/Science Education, edited by George M. Bodner and MaryKay Orgill (Prentice-Hall, Upper Saddle River, NJ, 2007) Chap. 7.

[29] Shanna R. Daly, Robin S. Adams, and George M. Bodner, "What does it mean to design? A qualitative investigation of design professionals' experiences,' Journal of Engineering Education 101, 187-219 (2012).

[30] Amy L. Micklos-Lewis and George M. Bodner, "Chemical reactions: What understanding do students with blindness develop?" Chemistry Education Research and Practice 14, 625636 (2013)

[31] Provi M. Mayo, "Critical theory," in Theoretical Frameworks for Research in Chemistry/Science Education, edited by George M. Bodner and MaryKay Orgill (Prentice-Hall, Upper Saddle River, NJ, 2007) Chap. 14.

[32] Audrey B. Champagne, Barbara E. Lovitts, and Betty Calinger, eds., This Year in School Science 1990: Assessment in Service of Instruction (American Association for the Advancement of Science, 1990).

[33] George Bodner, Daniel MacIsaac, and Scott White, "Action research: Overcoming the sports mentality approach to assessment/evaluation," University Chemistry Education 3, 3136 (1999).

[34] Jose P. Mestre, ed., Transfer of Learning from a Modern Multidisciplinary Perspective (Information Age Publishing, Greenwich, CT, 2005).

[35] Etienne Wenger, Communities of Practice: Learning, Mean- 
ing, and Identity (Cambridge University Press, Cambridge, 1998).

[36] William J. F. Hunter, "Action research as a framework for science education research," in Theoretical Frameworks for Research in Chemistry/Science Education, edited by George M. Bodner and MaryKay Orgill (Prentice-Hall, Upper Saddle River, NJ, 2007) Chap. 9.

[37] Stephen Kemmis and Robin McTaggart, The Action Research
Planner, 3rd ed. (Deakin University Press, Geelong, Victoria, Australia, 1988).

[38] Stephen Kemmis and Robin McTaggart, The Action Research Reader (Deakin University Press, Geelong, Victoria, Australia, 1990).

[39] Susan Rena Hanus Holladay, Action Research as the Vehicle for Curriculum Change in Analytical Chemistry: A Longitudinal Study, Ph.D. thesis, Purdue University, West Lafayette, IN (2001). 